\title{
Audit of outcomes following attendance at the City West drive-through IOP glaucoma clinic during the COVID-19 pandemic
}

\author{
Sarah Powell ${ }^{1} \cdot$ Emer Doolan $^{2} \cdot$ Karen Curtin $^{2} \cdot$ Aoife Doyle $^{2} \cdot$ Colm O'Brien $^{1}$
}

Received: 5 November 2021 / Accepted: 7 December 2021 / Published online: 16 January 2022

(c) The Author(s), under exclusive licence to Royal Academy of Medicine in Ireland 2021

\begin{abstract}
Background Glaucoma is the leading cause of irreversible blindness globally. During the COVID-19 pandemic, an enforced reduction in capacity resulted in the deferral of routine outpatient appointments for glaucoma patients.

Aim This study analyses patient outcomes following the establishment of a drive-through intra-ocular pressure (IOP) clinic during the COVID-19 pandemic to alleviate increased pressure on the tertiary glaucoma services at Royal Victoria Eye and Ear Hospital (RVEEH) and Mater Misericordiae University Hospital (MMUH) between August 2020 and June 2021.

Methods A 1-lane driveway system was established in a marquee on the grounds of City West hotel. IOPs were measured in patients' cars using a hand held iCare100 tonometer. Results were reviewed by a consultant ophthalmologist. At hospital follow-up clinic visits, IOP was measured using the Goldmann applanation tonometer (GAT).

Results Three hundred one patients of a total of 672 who attended the drive-through clinic have subsequently attended a designated hospital follow-up appointment. In this cohort, the mean drive-through iCare IOP of $19.4 \mathrm{mmHg} \pm 6.0$ was significantly higher $(<0.005)$ than the mean GAT IOP at the pre-drive through clinic visit $(16.3 \mathrm{mmHg} \pm 3.7)$ and the post drive-through hospital follow-up visit $(17.2 \mathrm{mmHg} \pm 4.1)$. Two hundred twenty-six $(75 \%)$ patients did not need any treatment change, $53(18 \%)$ required eye drop medication changes, $10(3 \%)$ underwent a laser procedure, $4(1 \%)$ required surgical intervention, and $8(3 \%)$ were discharged. When patient outcomes were analysed according to IOP grade assigned at the drive-through clinic, those with an iCare IOP $<21$ were significantly less likely to require a treatment change. The cohort with iCare IOP $\geq 30$ were significantly more likely to have a laser or surgical intervention.

Conclusion The implementation of a drive-through IOP clinic was a safe and effective way to monitor glaucoma patients during COVID-19, and identify those at high risk of poor IOP control or requiring a change in treatment.
\end{abstract}

Keywords COVID-19 · Drive-through intraocular pressure clinic · Glaucoma

\section{Introduction}

Glaucoma is the second leading cause of blindness in Ireland after age-related macular degeneration (ARMD), accounting for $12 \%$ of registrations with the National Council for the Blind in Ireland (NCBI) in 2003 [1]. In 2020, glaucoma was reported as the leading cause of preventable blindness in

Sarah Powell and Emer Doolan are joint first authors

Colm O'Brien

cobrien@mater.ie

1 Department of Ophthalmology, Mater Misericordiae University Hospital, Dublin, Ireland

2 Department of Ophthalmology, Royal Victoria Eye and Ear Hospital, Dublin, Ireland the United Kingdom (UK), accounting for almost one-third of new vision impairment certifications [2]. This was due to a relative decrease in registrations caused by ARMD and diabetic eye disease.

In 2017, the British Ophthalmological Surveillance unit found that up to 22 people per month suffered permanent and severe vision loss as a consequence of delayed followup due to insufficient capacity within hospital eye services [3]. The most common diagnosis in this group was glaucoma [4]. This finding led to recommendations specific to the subspecialty of glaucoma for clinical pathway redesign. National guidance has been issued regarding the use of 'virtual' glaucoma clinics to increase capacity [5]. Virtual clinics have been implemented in centres across the UK [6-9]. Fifty percent of respondents to a UK national survey of clinical leads carried out in 2016 were 
already utilising glaucoma virtual clinics, with a further $21.4 \%$ planning to establish ones. The majority of those running virtual clinics used this model of care for 'lower risk' patients such as ocular hypertensives and glaucoma suspects. [9] Remote decision-making using data collected from glaucoma patients has been shown to be both safe and efficient [8].

In Ireland, the National Care Plan for Ophthalmology aims for $80 \%$ of glaucoma patients to be managed in the primary care eye setting, but states that glaucoma as a disease lends itself to tele-medicine, virtual clinics and obtaining an expert opinion from a distant location is generally possible [10]. To date, one centre in Ireland has implemented a virtual glaucoma service. With the establishment of the first Community Eyecare centres in 2020, led by consultant medical ophthalmologists, plans to extend such clinics into the community are at an advanced stage and links to the tertiary glaucoma services and the expertise of a glaucoma consultant will be available.

The provision of safe and effective glaucoma care even prior to the COVID-19 pandemic was challenging. Increased virtual services were becoming the recommended method of monitoring. During the pandemic, an enforced reduction in capacity resulted in the deferral of routine outpatient appointments. Our literature review revealed strategies adopted to minimise the impact of delayed care worldwide. Some form of telehealth/telemedicine has been adopted in ophthalmological centres in the USA, UK, India, Hong Kong, and Singapore in response to the pandemic [11-15] subspecialties of medical retina, paediatric ophthalmology, neuro-ophthalmology, and glaucoma [14, 16-18]. Specific to glaucoma care, Bommakanti et al. developed a flexible and scalable scoring algorithm for patients with glaucoma that considers glaucoma severity and progression risk versus the presence of high-risk features for morbidity from COVID-19, using information from a large data repository. This facilitated the triage, postponing and rescheduling of ophthalmic appointments [19].

Drive-through IOP clinics were utilised for glaucoma patients in two centres in the USA and in Belfast during the pandemic [20,21]. Shah et al. compared subjects that received E-health visits versus subjects that received E-health visits with a drive-through IOP check. The rate of intervention was significantly higher in the group that received an IOP check [21].

Our aims with this study are to describe the establishment of a drive-through satellite IOP clinic in Dublin, Ireland, during the COVID-19 pandemic, and to determine patient outcomes in terms of IOP measurement and change in treatment following review back in the hospital setting. This was done to relieve pressure on the tertiary glaucoma services at the Royal Victoria Eye and Ear Hospital (RVEEH) and Mater Misericordiae University Hospital (MMUH).

\section{Methods}

This retrospective audit examined all MMUH and RVEEH glaucoma patients that attended the City West IOP drivethrough clinic initiative between August 2020 and June 2021 who were subsequently followed up in a face-to-face hospital outpatient clinic setting.

\section{Patient selection}

Medical records of MMUH (PatientCentre) and RVEEH (Electronic Patient Record system Medisight or Docman) patients who normally attended outpatient glaucoma clinics in both tertiary referral centres, and whose appointments were either cancelled or delayed due to COVID-19 were reviewed by an ophthalmologist. Information pertaining to each patients diagnosis, last clinic IOP, and current treatment regimen were recorded. All patients deemed eligible then received a phone invitation to attend City West drivethrough IOP clinic, and those that agreed to attend were subsequently sent an appointment letter and information leaflet by post, which contained written instructions detailing what the drive-through clinic process entailed.

Patients who attended CW drive through IOP clinic and who were included in this audit had a range of diagnoses, including ocular hypertension (OHT), primary open angle glaucoma (POAG), normal tension glaucoma (NTG), angle closure glaucoma (ACG), secondary glaucoma, and glaucoma suspects.

\section{City West IOP clinic process}

A 1-lane driveway system was established in a marquee on the grounds of City West hotel in Dublin. Patients, who were given 10-min appointment slots, drove into the marquee and lined up in their cars (Fig. 1). An ophthalmic nurse confirmed the patients identity, and conducted a COVID-19 screening questionnaire. All patients were required to wear face masks, and staff wore protective personal equipment (PPE). IOPs were measured in patients' cars using a hand

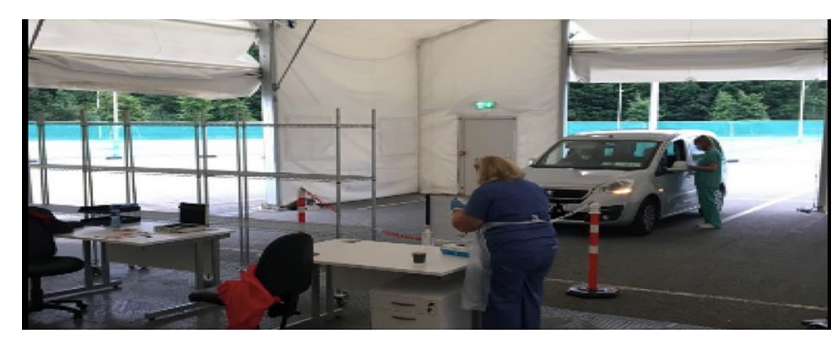

Fig. 1 City West drive-through intra-ocular pressure (IOP) clinic 
Table 1 Grading system as per City West IOP. Patients were graded per their IOP in one or both eyes

\begin{tabular}{ll}
\hline Grade & $\begin{array}{l}\text { City West IOP (in } \\
\text { one or both eyes) }\end{array}$ \\
\hline 1 & $<21$ \\
2 & $21-25$ \\
3 & $26-29$ \\
4 & $\geq 30$ \\
\hline
\end{tabular}

held iCare100 tonometer (iCare IC 100), which records the average of six IOP readings for each eye.

Results were input onto Medisight (RVEEH) or PatientCentre (MMUH), where they could then be reviewed by a consultant ophthalmologist, and a decision about when to organise an outpatient follow-up appointment for each patient was made. At MMUH, subjects were all seen back in a face-to-face doctor-led clinic. At RVEEH, subjects were distributed between face-to-face doctor-led clinics, face-toface nurse-led clinics, and the virtual glaucoma assessment clinic (GAC) which is in operation since 2019. At the GAC, a nurse collects data including GAT, 3D disc photographs with a Kowa nonmydriatic WX 3D camera (Kowa, Tokyo, Japan), and Humphrey visual field SITA 24-2 (Humphrey Instruments, Dublin, CA, USA). These results are later reviewed by an ophthalmologist.

\section{Patient follow-up}

Three hundred one subjects in total (179 from RVEEH and 122 from MMUH) were followed up by an ophthalmologist in a virtual (following nurse review) or face-to-face clinic after their City West IOP check between September 2020 and June 2021. These patients were graded according to their City West IOP, as described in Table 1.

At follow-up face-to-face clinic visits in RVEEH and MMUH, IOP was measured using the gold standard Goldmann applanation tonometer (GAT), and patient outcomes were recorded and grouped accordingly — no change in treatment, change in medication, laser treatment, surgical intervention or discharge.

\section{Early review/follow-up criteria}

Criteria for early review/follow-up included IOP $>/+4 \mathrm{mmHg}$ higher versus last clinic GAT IOP or IOP $>21$ plus self-reporting of symptoms of ocular discomfort, poor adherence to drops or symptoms of drop intolerance.

\section{Statistical analyses}

Comparison of the IOP data between the two sites was carried out with an independent two-sample $T$ test. Comparison of the drive-through IOP with the pre drive-through and post drive-through IOP was done with a one-way ANOVA test, with Bonferroni-corrected post-test paired $t$-test. Comparison of the drive-through IOP in the subgroups of subjects with ocular hypertension, glaucoma (incorporating the subgroups of POAG, NTG, ACG, and secondary glaucoma) and glaucoma suspects was carried out with a one-way ANOVA test, with Bonferronicorrected post-test paired $t$-test. Patient outcomes were analysed across the same three diagnostic groups with a chi-squared test for independence, with Bonferroni adjustment. Patient outcomes between sites were also analysed in this way, as were patient outcomes according to IOP grade. All statistical and graphical analyses were performed using Microsoft ${ }^{\circledR}$ Excel for Mac Version 16.16.27 and GraphPad Prism version 9.2.0.

\section{Results}

Between September 2020 and June 2021, 672 subjects attended the drive-through clinic: 138 from MMUH and 534 from RVEEH. At the time the audit was conducted (June 2021), 301 of these (122 from MMUH and 179 from RVEEH) have subsequently attended their designated followup appointments. Diagnoses of all subjects from both sites are as depicted in Table 2.
Table 2 Diagnosis of all subjects overall, then subdivided by site

\begin{tabular}{|c|c|c|c|c|c|c|}
\hline & \multicolumn{2}{|l|}{ Overall } & \multicolumn{2}{|l|}{ RVEEH } & \multicolumn{2}{|l|}{ MMUH } \\
\hline & $n=301$ & $\%$ & $n=179$ & $\%$ & $n=122$ & $\%$ \\
\hline OHT & 87 & $29 \%$ & 52 & $29 \%$ & 35 & $29 \%$ \\
\hline NTG & 13 & $4 \%$ & 2 & $1 \%$ & 11 & $9 \%$ \\
\hline POAG & 65 & $22 \%$ & 31 & $17 \%$ & 34 & $28 \%$ \\
\hline ACG & 25 & $8 \%$ & 13 & $7 \%$ & 12 & $10 \%$ \\
\hline Glaucoma suspects & 76 & $25 \%$ & 64 & $36 \%$ & 12 & $10 \%$ \\
\hline Secondary glaucoma & 35 & $12 \%$ & 17 & $9 \%$ & 18 & $15 \%$ \\
\hline
\end{tabular}

RVEEH Royal Victoria Eye and Ear Hospital; MMUH Mater Misericordiae University Hospital; OHT ocular hypertension; $N T G$ normal tension glaucoma; $P O A G$ primary open angle glaucoma; $A C G$ angle closure glaucoma 
Mean drive-through iCare IOP overall was 19.4 $\mathrm{mmHg} \pm 6.0$. Mean drive-through IOP in the MMUH group was $19.1 \mathrm{mmHg} \pm 6.2$ compared to $19.6 \mathrm{mmHg} \pm 6.0$ in the RVEEH patient cohort. There was no significant difference found between groups $(p=0.5)$. Mean drivethrough IOP in the OHT subgroup was significantly higher at $21.7 \mathrm{mmHg} \pm 6.0$ than that of the glaucoma and glaucoma suspects groups $(18.7 \mathrm{mmHg} \pm 6.2$ and $18.1 \pm 5.1$ respectively) ( $p=0.02)$ (Fig. 2).

Mean drive-through iCare IOP in the group overall $(19.4 \mathrm{mmHg} \pm 6.0)$ was significantly higher than both the mean GAT IOP at the pre-drive through OPD visit $(16.3 \mathrm{mmHg} \pm 3.7)$ and the mean GAT IOP at the post drive-through follow-up visit $(17.2 \mathrm{mmHg} \pm 4.1)(p=0.01)$ (Fig. 3).

The change in treatment outcomes of patients is shown in Table 3.

The difference in frequency of outcomes between the two sites was found to be non-significant. Where a laser intervention was required in the group overall $(n=10)$, these included selective laser trabeculoplasty $(n=5)$, peripheral iridotomy $(n=3)$, and cyclodiode laser $(n=2)$. Where a surgical intervention was required $(n=4)$, these included trabeculectomy $(n=1)$, cataract surgery $(n=2)$, and cataract surgery combined with cyclodiode laser $(n=1)$.

When patient outcomes were analysed according to diagnosis (Table 4), the patients that were glaucoma suspects were significantly more likely to be discharged from the glaucoma service than subjects from the other two groups. There was otherwise no significant difference in frequency of outcomes.

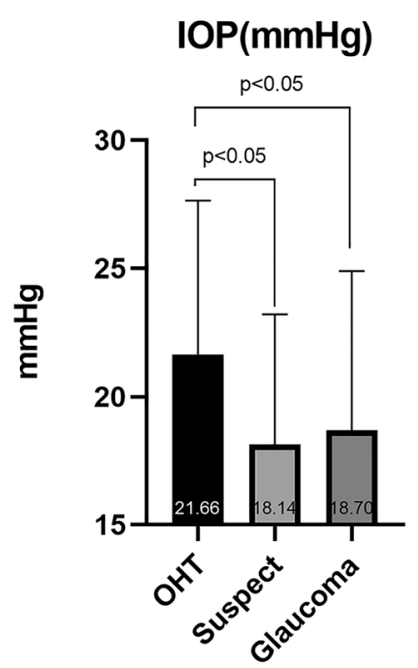

Fig. 2 Drive-through IOP (with iCare) compared between diagnostic subgroups. OHT, ocular hypertension; Suspect, glaucoma suspect; Glaucoma, includes POAG, NTG, ACG and secondary glaucoma subgroups

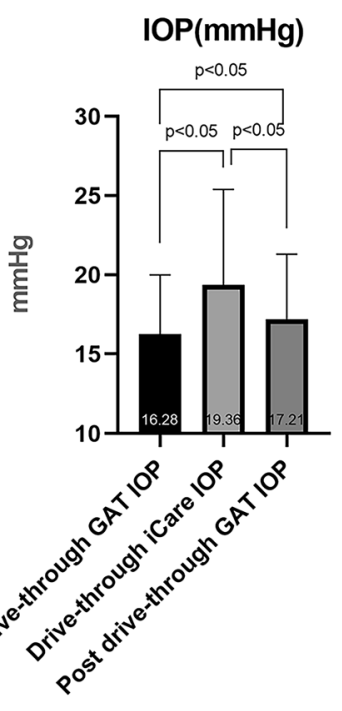

Fig. 3 Drive-through IOP (with iCare) compared to the pre drivethrough GAT IOP and post drive-through GAT IOP recorded for each subject

In this cohort of 301 patients, 162 patients had iCare IOP $<21 \mathrm{mmHg}, 69$ patients had iCare IOP between 21 and $25 \mathrm{mmHg}, 34$ between 26 and $30 \mathrm{mmHg}$, and 37 patients had iCare readings $\geq 30 \mathrm{mmHg}$. All notes of patients with iCare readings $>21 \mathrm{mmHg}$ were reviewed shortly after $\mathrm{CW}$ by a clinician to determine how urgently they needed hospital review. When patient outcomes were analysed according to iCare IOP measurement assigned at the drive-through clinic (Table 5), those in the group with IOP $<21$ were significantly more likely to have no change to treatment. Those in the group with IOP $\geq 30$ were significantly more likely to have change in treatment, as well as being more likely to have a laser or surgical intervention. There was otherwise no significant difference in frequency of outcomes across the IOP subgroups.

\section{Discussion}

The COVID-19 pandemic has shaped a new landscape by which ophthalmic care in general, and glaucoma care in particular, will be delivered in the future. In March 2020, all elective and non-urgent ophthalmic care was cancelled in Ireland whilst the Health Service Executive (HSE) focused on safeguarding intensive care unit capacities and halting the inexorable spread of COVID-19 in the community and in hospitals nationwide.

As elective and non-urgent hospital care was cancelled in order to prioritise and provide appropriate medical care for those sickest, almost overnight ophthalmologists found themselves in the difficult position of being unable to see and examine those patients deemed to be 
Table 3 Patient outcomes for all subjects, then subdivided by site

\begin{tabular}{|c|c|c|c|c|c|c|}
\hline & \multicolumn{2}{|l|}{ Overall } & \multicolumn{2}{|l|}{ RVEEH } & \multicolumn{2}{|l|}{ MMUH } \\
\hline & $n=301$ & $\%$ & $n=179$ & $\%$ & $n=122$ & $\%$ \\
\hline No change & 226 & 75 & 131 & 73 & 95 & 78 \\
\hline Med & 53 & 18 & 32 & 18 & 21 & 17 \\
\hline Laser & 10 & 3 & 6 & 3 & 4 & 3 \\
\hline Surgery & 4 & 1 & 3 & 2 & 1 & 1 \\
\hline Discharged & 8 & 3 & 7 & 4 & 1 & 1 \\
\hline
\end{tabular}

RVEEH Royal Victoria Eye and Ear Hospital; MMUH Mater Misericordiae University Hospital non-urgent in-person. Initiatives such as telemedicine, phone consultations, and virtual clinics rose to prominence as new, effective methods by which to provide efficient, effective ophthalmic care [22, 23]. However, telemedicine has clear drawbacks in ophthalmic care, and in particular in glaucoma, where measurements and values obtained at real patient visits are a critical part of the treatment decision-making process. Agreed Guidelines were drawn up by RVEEH and MMUH under the auspices of the Ireland East Hospital Group to ensure that those in urgent need of glaucoma-related care would be seen, but the majority of glaucoma patients did not fall into this category. Following a 2-3 months closure to direct consultations, the ability to return to normal capacity was greatly impaired by new infection control guidelines, the continuing high risk of COVID transmission and the need for social distancing and adequate ventilation in busy and previously overcrowded environments, as well as reluctance by patients to enter the hospital environment due to perceived high risk of transmission amongst healthcare workers.

The Royal College of Ophthalmologists (RCOphth) published a set of guidelines pertaining to the delivery of glaucoma care during COVID-19, outlining care pathways for glaucoma patients during the pandemic and providing advice to ophthalmologists regarding the stratification of patients who need urgent care, simultaneously balancing the risk of COVID-19 and its disease sequelae, with the consequences of permanent vision loss due to treatment delays [22, 24].
One large UK eyecare centre increased the provision of technician-led remote monitoring clinics to facilitate a major shift to consultant-led virtual review. This centre also recommended that shared care collaborations between commissioners, primary care settings, and high street optometry providers must be accelerated in order to facilitate the capture of patient data closer to home, away from the hospital environment, but with the capability for all necessary data to be available for consultant-led decision making [14].

Husain et al. whilst giving perspectives on management of glaucoma patients during the pandemic in Singapore describe the increased utilisation of video consultations, both with and without the collection of IOP, visual field and posterior segment photography data in satellite units. [25] During their pilot trials of this model of care, a satisfaction survey on glaucoma patients/glaucoma suspects showed that $94.8 \%$ agreed that the care they received was satisfactory.

An enforced reduction in capacity during COVID-19 resulted in the deferral of routine outpatient appointments for glaucoma patients. It was determined that a drive-through IOP clinic using the iCare tonometer would address many of the concerns above. It was decided that a short questionnaire (Appendix 1), in conjunction with an iCare IOP measurement, would provide sufficient information to identify patients at high risk of glaucoma progression, to enable their swift return to the main glaucoma clinic for assessment regarding medication changes or possible intervention. IOP is the main modifiable risk
Table 4 Patient outcomes by diagnosis

\begin{tabular}{|c|c|c|c|c|c|c|}
\hline & \multicolumn{2}{|l|}{ OHT } & \multicolumn{2}{|c|}{ Glaucoma suspects } & \multicolumn{2}{|c|}{ Glaucoma } \\
\hline & $n=87$ & $\%$ & $n=76$ & $\%$ & $n=138$ & $\%$ \\
\hline No change & 68 & 78 & 58 & 76 & 100 & 72 \\
\hline Med & 16 & 18 & 10 & 13 & 27 & 20 \\
\hline Laser & 1 & 1 & 2 & 3 & 7 & 5 \\
\hline Surgery & 1 & 1 & 0 & 0 & 3 & 2 \\
\hline $\begin{array}{l}\text { Discharged at follow- } \\
\text { up }\end{array}$ & 1 & 1 & 6 & 8 & 1 & 1 \\
\hline
\end{tabular}

OHT ocular hypertension. Glaucoma includes subgroups of POAG, NTG, ACG, and secondary glaucoma 
Table 5 Patient outcomes by IOP grades $<21 \mathrm{mmHg}$, $21-25 \mathrm{mmHg}, 26-29 \mathrm{mmHg}$, and $\geq 30 \mathrm{mmHg}$

\begin{tabular}{|c|c|c|c|c|c|c|c|c|}
\hline & \multicolumn{2}{|l|}{$\mathrm{IOP}<21$} & \multicolumn{2}{|c|}{ IOP $21-25$} & \multicolumn{2}{|c|}{ IOP 26-29 } & \multicolumn{2}{|c|}{$\mathrm{IOP} \geq 30$} \\
\hline & $n=162$ & $\%$ & $n=69$ & $\%$ & $n=34$ & $\%$ & $n=37$ & $\%$ \\
\hline No change & 135 & $83 \%$ & 50 & $72 \%$ & 23 & $68 \%$ & 18 & $49 \%$ \\
\hline Med & 21 & $13 \%$ & 17 & $25 \%$ & 6 & $18 \%$ & 10 & $27 \%$ \\
\hline Laser & 1 & $1 \%$ & 0 & $0 \%$ & 4 & $12 \%$ & 5 & $14 \%$ \\
\hline Surgery & 0 & $0 \%$ & 0 & $0 \%$ & 0 & $0 \%$ & 4 & $11 \%$ \\
\hline Discharged & 5 & $3 \%$ & 2 & $3 \%$ & 1 & $3 \%$ & 0 & $0 \%$ \\
\hline
\end{tabular}

factor for disease progression, and issues relating to drop use, compliance, toxicity, and dryness were identified by the questionnaire. The clinic was located in an off-site location from the main hospitals, and therefore negated problems such as car-parking, and also provided a more attractive option for patients with concerns about entering a hospital environment during COVID-19.

\section{iCare tonometry}

Accurate IOP measurement is an integral component of every routine ophthalmic examination. Glaucoma as a subspecialty, in particular, relies heavily on accurate IOP measurement as a critical parameter in the formulation of management plans and treatment regimens for patients [26]. Whilst GAT remains the gold standard and most reliable IOP measurement used in clinical practice, [27] in recent years several alternative IOP measurement instruments and techniques have been developed and introduced into ophthalmic care in an outpatient setting [28]. Amongst these is the iCare rebound tonometer, a small hand-held machine with a single-use magnetised probe which records the average reading of six IOP measurements per eye. When compared to GAT, iCare tonometry is a quicker, more comfortable IOP measurement for patients, it is anaesthetic and eye drop free, and it requires very little staff training [29, 30]

\section{iCare versus GAT}

Several studies have compared the efficacy of the iCare tonometer to the GAT method, with largely reassuring results over a low to moderate IOP range [31]. Chen et al. analysed iCare and GAT IOP measurements in 200 subjects and found that there was no statistical difference between the groups, with $>90 \%$ IOP measurements within $\pm 3 \mathrm{mmHg}$ in low and normal IOP range, and $80 \%$ were within $\pm 3 \mathrm{mmHg}$ in elevated IOP cohort [32]. Similarly, Scuduri et al. compared iCare and GAT IOP measurements in 97 subjects, and their results showed that the iCare method was agreeable and highly consistent with GAT. [33] iCare tonometry has also been shown to be a reliable IOP measuring tool in inexperienced hands. Abraham et al. showed that non-ophthalmologists could accurately measure IOP using iCare tonometry, and therefore deduced it is an accurate and acceptable IOP measurement method, especially in situations where GAT is unavailable, or when patients are not suitable for IOP measurements by GAT [33, 34].

However, some studies have found that iCare accuracy is inconsistent when compared to GAT. Nakamura et al. found that although iCare was agreeable with GAT, the device tended to significantly overestimate IOP more than GAT as patients' central corneal thickness (CCT) was thicker [35]. Kim et al. analysed iCare PRO versus GAT in 86 glaucoma patients (172 eyes) and found that iCare was a reliable substitute for GAT, although it somewhat overestimated IOP reading especially at lower IOP values when compared to GAT. Contrary to Nakura et al. iCare PRO was unaffected by CCT in this study. Tamaçelik et al. found that iCare was highly agreeable with GAT especially in normal IOP range (10-22 mmHg); however, they found significant discrepancies between the two methods in IOP ranges $<9$ and $>22$. Similar to Nakura et al. they concluded that CCT had no effect on iCare measurements in this study [36].

In our study, we found that the mean iCare IOP in the overall cohort was significantly higher than both mean GAT IOP at the pre-drive through clinic and outpatient follow-up clinic. This may suggest that in our patient cohort, iCare overestimated the IOP when compared to GAT; however, it is difficult to definitively conclude this. Two methods of IOP measurement were performed at different timepoints (pre-drive through, drive through, and post-drive through follow-up), and at various times throughout the day, thereby making a conclusion difficult to generate. Furthermore, CCT measurement was not collected on all patients; therefore, we cannot draw a conclusion as to whether IOP as measured by iCare was influenced by CCT in our patient group.

\section{Patient diagnoses}

Overall, the most common diagnoses between the two groups were OHT, followed by glaucoma suspects and 
POAG. OHT was the most common diagnosis amongst the MMUH patient cohort (29\% versus 29\% in RVEEH), whereas glaucoma suspects was the number one diagnosis in the RVEEH group (36\%). There is a significantly higher percentage of glaucoma suspects in the RVEEH patient cohort when compared to MMUH (10\%), possibly due to the higher number of glaucoma suspect patients in virtual clinics. Furthermore, a much higher percentage of POAG patients were observed in the MMUH patient cohort when compared to RVEEH (28\% versus 17\%). A significant proportion of the patients came from a pre-existing stable glaucoma nurse-led clinic as all patients booked to attend that clinic were invited to attend the drive-through clinic option.

\section{Patient outcomes}

Overall, $45 \%$ of all patients who attended the drivethrough clinic have attended subsequent follow-up outpatient appointments. Seventy-five percent of these patients (RVEEH: 73\%, MMUH 78\%) needed no treatment change after their follow-up appointments, and could continue with their current treatment regimen. Eighteen percent (RVEEH: 18\%, MMUH: 17) required a change in medication that was due to elevated IOP (Table 4). Overall, the OHT cohort were the most likely group of patients not to need any changes in medication (78\%) when compared to glaucoma suspects (76\%) and patients diagnosed with glaucoma (72\%). As a sub-group, patients with glaucoma were most likely to have their medication changed (20\%) versus OHT and glaucoma suspects (18\% and 13\%, respectively). This is not surprising given that these patients have existing visual field loss and are more at risk of needing further intervention. As expected, patients with IOP $<21$ were most likely to need no change in treatment (83\%) (Table 5) and subjects with IOP $\geq 30$ were most likely to need a change in medication (27\%), undergo laser (14\%) or surgical intervention (11\%). The percentage of NTG sent to the CW clinic was low. NTG is a condition in which treatment change is more likely to be made based on changes in the visual field, optic nerve examination, medical history, or other ancillary tests as opposed to the IOP alone. Fluctuations in the IOP are arguably of less importance in these patients unless additional information is available to correlate with the IOP.

It is not yet known the extent that the impact of the reduction and disruption to the provision of ophthalmic care during COVID-19 will have on glaucoma patients in the future, though it is reasonable to assume that there will unfortunately be considerable adverse downstream consequences for patients. Fortner and Lindsey reported increased rates of glaucoma progression in a group of patients who experienced delayed ophthalmic care during the pandemic at a US centre (37.5\% during the pandemic versus $17.0 \%$ pre pandemic).[37] Pujari et al. assessed the impact of COVID-19 on glaucoma patients using the patient-reported outcome and experience measure (POEM). They found that patients were more uncertain regarding how their glaucoma was being managed, and more anxious about disease progression [38]. These studies highlight the fundamental importance of the development of innovative measures such as drive-through IOP clinics in order to maintain effective delivery of glaucoma care, but also to lessen patient anxiety and worry surrounding their treatment and prognosis, especially during the uncertainty of COVID-19.

\section{Study limitations}

There are a number of limitations of this retrospective audit. Firstly, not all patients had Humphrey visual fields (HVF) performed at follow-up OPD visits; thus, it is difficult to ascertain the rates of glaucoma progression amongst this cohort of patients. Over the next 12 months, we envisage this will be done for the full cohort of 672 patients who attended $\mathrm{CW}$ drive-through clinic, and the outcomes reported. Secondly, patients with a wide range of risk factors and varying degrees of disease severity were selected from both centres. In particular, RVEEH patients were selected from either a nurse-led, virtual clinic or from main OPD glaucoma clinic, whereas all of the MMUH patients were selected from main OPD glaucoma clinics. In general, patients attending the virtual/nurse-led clinics are stable patients, and therefore there may be a higher incidence of treatment change or interventions in the main glaucoma clinic cohort.

\section{Conclusion}

In summary, the implementation of a drive-through satellite IOP clinic in Dublin was a safe and effective way of stratifying and identifying high-risk glaucoma patients during the COVD-19 pandemic in Ireland whilst simultaneously maintaining patient and staff safety. As health systems and economies across the globe recover from COVID-19, and as we emerge into an uncertain post-COVID future, ophthalmology must seek more efficient methods of stratifying risk and reducing number of in-person visits for patients in the low-risk category to allow us to detect those at highest risk of progression. It is hoped that in this way we can reduce the number progressing due to delayed care. The development of virtual clinics such as this one described, alongside advances in technology, imaging technologies, and artificial intelligence (AI), renders ophthalmology as one of the specialities most poised to pave the way for the transformation of healthcare and to ensure the delivery of high-quality ophthalmic patient care. 


\section{Appendix 1. Glaucoma CW IOP \\ drive-through assessment form}

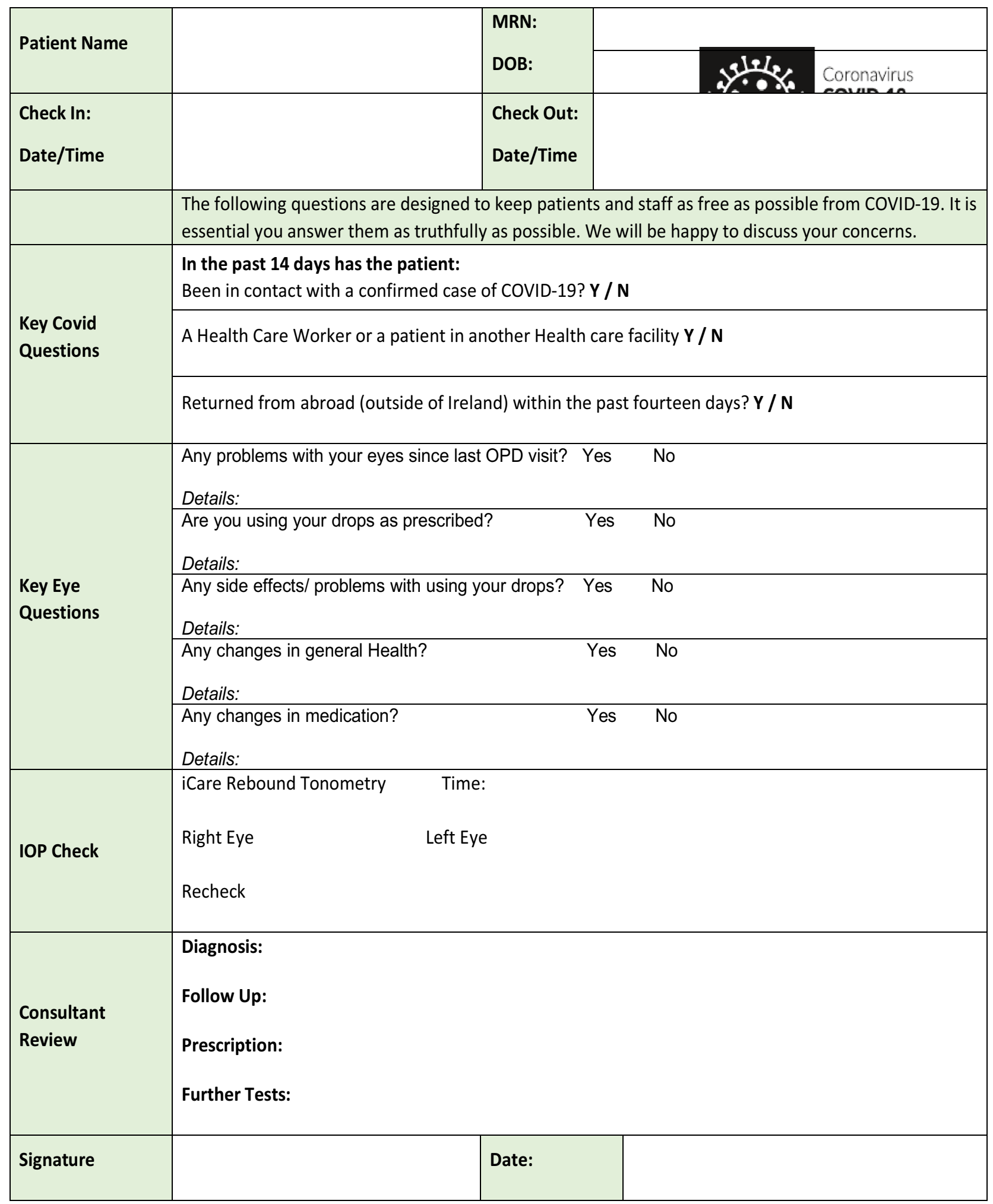




\section{Declarations}

Ethics approval The initiative was approved by the Chief Executive Officer of the Ireland East Health Group and management group at RVEEH as a valuable initiative to improve delivery of outpatient services during the pandemic to patients who would not otherwise have been able to attend, due to COVID-19 restrictions. Ethical committee approval for the clinic was not felt to be necessary as it improved the care options available to these patients and was offered on an opt-in basis following phone call and explanation to the patient. No patients are identifiable from the data presented.

\section{References}

1. Kelliher C, Kenny D, O'Brien C (2006) Trends in blind registration in the adult population of the Republic of Ireland 1996-2003. Br J Ophthalmol 90(3):367-371. https://doi.org/10.1136/bjo.2005. 075861

2. Rahman F, Zekite A, Bunce C et al (2020) Recent trends in vision impairment certifications in England and Wales. Eye 34(7):12711278. https://doi.org/10.1038/s41433-020-0864-6

3. Healthcare Safety Investigation Branch (2020) Lack of timely monitoring of patients with glaucoma. 3-64. https://www.hsib.org. uk/documents/199/hsib_report_lack_timely_monitoring_patients_ glaucoma.pdf. Accessed 20 July 2021

4. Foot B, MacEwen C (2017) Surveillance of sight loss due to delay in ophthalmic treatment or review: frequency, cause and outcome. Eye (Lond) 31(5):771-775. https://doi.org/10.1038/eye.2017.1

5. The Royal College of Ophthalmologists (2016) Standards for virtual clinics in glaucoma care in the NHS hospital eye service. Ophthalmic Serv Guid. https://www.rcophth.ac.uk/wpcontent/ uploads/2017/03/Virtual-Glaucoma-Clinics.pdf. Accessed 20 July 2021

6. Trikha S, Macgregor C, Jeffery M, Kirwan J (2012) The Portsmouth-based glaucoma refinement scheme: a role for virtual clinics in the future? Eye (Lond) 26(10):1288-1294. https://doi.org/ 10.1038/eye.2012.120

7. Mostafa I, Bianchi E, Brown L, Tatham AJ (2021) What is the best way to measure intraocular pressure (IOP) in a virtual clinic? Eye 35(2):448-454. https://doi.org/10.1038/s41433-020-0868-2

8. Clarke J, Puertas R, Kotecha A et al (2020) Virtual clinics in glaucoma care: face-to-face versus remote decision-making. Br J Ophthalmol 101(7):892 LP - 895. https://doi.org/10.1136/ bjophthalmol-2016-308993

9. Gunn PJG, Marks JR, Au L, Waterman H, Spry PGD, Harper RA (2018) Acceptability and use of glaucoma virtual clinics in the UK: a national survey of clinical leads. BMJ Open Ophthalmol 3(1):e000127. https://doi.org/10.1136/bmjophth-2017-000127

10. Power W, Barry P, Moriarty P, Kelly S. National Clinical Programme for Ophthalmology:Model of Eye Care: Draft Report. Published online 2017. http://hdl.handle.net/10147/622544. Accessed 20 July 2021

11. Parikh D, Armstrong G, Liou V, Husain D (2020) Advances in telemedicine in ophthalmology. Semin Ophthalmol 35(4):210-215. https://doi.org/10.1080/08820538.2020.1789675

12. Jayadev $C$, Mahendradas $P$, Vinekar A et al (2020) Tele-consultations in the wake of COVID-19 - suggested guidelines for clinical ophthalmology. Indian J Ophthalmol 68(7). https://journals.lww. com/ijo/Fulltext/2020/68070/Tele_consultations_in_the_wake_ of_COVID_19_.20.aspx. Accessed 20 July 2021

13. Wong JKW, Shih KC, Chan JCH, Lai JSM (2021) Teleophthalmology amid COVID-19 pandemic-Hong Kong experience.
Graefes Arch Clin Exp Ophthalmol 259(6):1663. https://doi.org/ 10.1007/s00417-020-04753-1

14. Jayaram H, Strouthidis NG, Gazzard G (2020) The COVID19 pandemic will redefine the future delivery of glaucoma care. Eye (Lond) 34(7):1203-1205. https://doi.org/10.1038/ s41433-020-0958-1

15. Khor WB, Yip L, Zhao P et al (2020) Evolving practice patterns in Singapore's public sector ophthalmology centers during the COVID-19 pandemic. Asia-Pacific J Ophthalmol (Philadelphia, Pa) 9(4):285-290. https://doi.org/10.1097/APO. 0000000000000306

16. Moss HE, Lai KE, Ko MW (2020) Survey of telehealth adoption by neuro-ophthalmologists during the COVID-19 pandemic: benefits, barriers, and utility. J Neuroophthalmol 40(3):346355. https://doi.org/10.1097/WNO.0000000000001051

17. Ko MW, Busis NA (2020) Tele-Neuro-Ophthalmology: Vision for 20/20 and Beyond. J Neuro Ophthalmol 40(3). https://journals. lww.com/jneuro-ophthalmology/Fulltext/2020/09000/Tele_Neuro_ Ophthalmology_Vision_for_20_20_and.14.aspx. Accessed 20 July 2021

18. Deshmukh AV, Badakere A, Sheth J et al (2020) Pivoting to teleconsultation for paediatric ophthalmology and strabismus: our experience during COVID-19 times. Indian J Ophthalmol 68(7):1387-1391. https://doi.org/10.4103/ijo.IJO_1675_20

19. Bommakanti NK, Zhou Y, Ehrlich JR et al (2020) Application of the Sight Outcomes Research Collaborative Ophthalmology Data Repository for triaging patients with glaucoma and clinic appointments during pandemics such as COVID-19. JAMA Ophthalmol 138(9):974-980. https://doi.org/10.1001/ jamaophthalmol.2020.2974

20. Baughman BD, Hansemann BK, Shah MM, Weizer JS (2021) Drivethrough intraocular pressure checks during the COVID-19 pandemic. J Glaucoma 30(3). https://journals.lww.com/glaucomajournal/Fulltext/ 2021/03000/Drive_through_Intraocular_Pressure_Checks_During.5. aspx. Accessed 20 July 2021

21. Shah K, Ooms A, Khouri AS, Habiel M (2021) Optimization of glaucoma management during a pandemic: drive-through IOP checks. Invest Ophthalmol Vis Sci 62(8):1619

22. Holland LJ, Kirwan JF, Mercieca KJ. Effect of COVID-19 pandemic on glaucoma surgical practices in the UK. Br J Ophthalmol. Published online April 30, 2021. https://doi.org/10.1136/ bjophthalmol-2021-319062

23. Vinod K, Sidoti PA (2021) Glaucoma care during the coronavirus disease 2019 pandemic. Curr Opin Ophthalmol 32(2). https://journals.lww.com/co-ophthalmology/Fulltext/2021/ 03000/Glaucoma_care_during_the_coronavirus_disease_ 2019.2.aspx. Accessed 20 July 2021

24. Liebmann JM (2021) Ophthalmology and glaucoma practice in the COVID-19 Era. J Glaucoma 29(6). https://journals.lww.com/ glaucomajournal/Fulltext/2020/06000/Ophthalmology_and_ Glaucoma_Practice_in_the.1.aspx. Accessed 20 July 2021

25. Husain R, Zhang X, Aung T (2020) Challenges and lessons for managing glaucoma during COVID-19 pandemic: perspectives from Asia. Ophthalmology 127(9):e63-e64. https://doi.org/10. 1016/j.ophtha.2020.05.042

26. Crawley L, Zamir SM, Cordeiro MF, Guo L (2012) Clinical options for the reduction of elevated intraocular pressure. Ophthalmol Eye Dis 4:OED.S4909. https://doi.org/10.4137/oed.s4909

27. Özcura F, Yildirim N, Şahin A, Çolak E (2015) Comparison of Goldmann applanation tonometry, rebound tonometry and dynamic contour tonometry in normal and glaucomatous eyes. Int J Ophthalmol 8(2):299-304. https://doi.org/10.3980/j.issn. 2222-3959.2015.02.15

28. ElMallah MK, Asrani SG (2008) New ways to measure intraocular pressure. Curr Opin Ophthalmol 19(2). https://journals.lww.com/ 
co-ophthalmology/Fulltext/2008/03000/New_ways_to_measure_ intraocular_pressure.8.aspx. Accessed 20 July 2021

29. Pakrou N, Gray T, Mills R et al (2008) Clinical comparison of the Icare tonometer and Goldmann applanation tonometry. J Glaucoma 17(1). https://journals.lww.com/glaucomajournal/Fulltext/2008/01000/ Clinical_Comparison_of_the_Icare_Tonometer_and.10.aspx. Accessed 20 July 2021

30. Takagi D, Sawada A, Yamamoto T (2017) Evaluation of a new rebound self-tonometer, Icare HOME: comparison with Goldmann applanation tonometer. J Glaucoma 26(7). https://journals. lww.com/glaucomajournal/Fulltext/2017/07000/Evaluation_of_a_ New_Rebound_Self_tonometer,_Icare.3.aspx. Accessed 20 July 2021

31. Kontiola A, Puska P (2004) Measuring intraocular pressure with the Pulsair 3000 and Rebound tonometers in elderly patients without an anesthetic. Graefe's Arch Clin Exp Ophthalmol 242(1):3-7. https://doi.org/10.1007/s00417-003-0671-3

32. Chen M, Zhang L, Xu J et al (2019) Comparability of three intraocular pressure measurement: iCare pro rebound, noncontact and Goldmann applanation tonometry in different IOP group. BMC Ophthalmol 19(1):225. https://doi.org/10.1186/ s12886-019-1236-5

33. Scuderi GL, Cascone NC, Regine F et al (2010) Validity and limits of the rebound tonometer (ICare $®$ ): clinical study. Eur J Ophthalmol 21(3):251-257. https://doi.org/10.5301/EJO.2010.3712
34. Abraham LM, Epasinghe NCR, Selva D, Casson R (2008) Comparison of the ICare ${ }^{\circledR}$ rebound tonometer with the Goldmann applanation tonometer by experienced and inexperienced tonometrists. Eye 22(4):503-506. https://doi.org/10.1038/sj.eye. 6702669

35. Nakamura M, Darhad U, Tatsumi Y et al (2006) Agreement of rebound tonometer in measuring intraocular pressure with three types of applanation tonometers. Am J Ophthalmol 142(2):332334. https://doi.org/10.1016/j.ajo.2006.02.035

36. Tamçelik N, Atalay E, Cicik E, Özkök A (2015) Comparability of Icare Pro rebound tonometer with Goldmann applanation and noncontact tonometer in a wide range of intraocular pressure and central corneal thickness. Ophthalmic Res 54(1):18-25. https:// doi.org/10.1159/000381781

37. Fortner R, Lindsey J (2021) Impact of the COVID19 pandemic on glaucoma patients: did delay in elective care lead to progression of disease? Invest Ophthalmol Vis Sci 62(8):1739

38. Pujari R, Chan G, Tapply I et al (2021) The impacts of COVID-19 on glaucoma patient outcomes as assessed by POEM. Eye Published online. https://doi.org/10.1038/s41433-021-01425-0

Publisher's Note Springer Nature remains neutral with regard to jurisdictional claims in published maps and institutional affiliations. 